\title{
A review work of urban ecosystem services and their interactions with dweller demand factors in modern China
}

\author{
Liang Zhao ${ }^{1,2}$ \\ ${ }^{1}$ Shenzhen Insitute, Chinese Academy of Urban Planning and Design, Shennan Street 7006, 518040 Shenzhen, China \\ ${ }^{2}$ The Faculty of Architecture, Dresden University of Technology, Institute for Urban Development, Zellescher Weg 17, D-01062 \\ Dresden, Germany
}

\begin{abstract}
Nowadays, various urban ecosystem services (UES) provided by urban green infrastructure (UGI) have been the concern of scholars worldwide. And as China being recognized as a living laboratory in sustainable studies, concerns toward UES provided by UGI and factors of urban dweller demands is definitely required. However, for related reviews and special discussions are lacking until now, this study calculated the types of UES and demand concerns with a collection of 54 Chinese and 51 English articles in UES studies, 162 Chinese and 26 English articles in urban dweller research. In addition, with detailed discussions through spatial distributions, perspectives, and methodologies, comprehensive analyses were conducted and unique features were summarized to back up other nations or situations worldwide.
\end{abstract}

\section{Introduction}

Nowadays, human demands have changed significantly, from basic needs such as sufficient food to more explicit attention to services that improve the quality of life [1]. Satisfaction in all aspects of urban dweller demands (i.e., physical, mental, social, cultural, and psychological, etc.) would be the driver for further socioeconomic development, cultural transformation, and technological innovation. And among all the urban elements, urban green infrastructure (UGI) [variously labeled as urban green, urban plant, urban vegetation, etc., and includes urban forests, parks, allotments, street trees, green roofs, etc. [2] is the most focused in terms of being parts of the urban physical environment and directly affecting dwellers through socioeconomic and even mentality. UGI has been widely acknowledged to increase environmental quality through air purification, microclimate regulation, noise reduction, and other methodologies [3-5]. Moreover, UGI can offer socioeconomic, cultural, and psychological benefits with recreation and nature experience services [6-7]. These "ecosystem services" could satisfy dweller demands, with detailed definitions and classifications found in related report work [8]. Although several studies have investigated human-environment interactions [9-10] and recent urban ecosystem demands in Europe [11-13], the investigation of dweller demands as a background to UES is still largely lacking in Asia and clearly requires increased attention worldwide.

For China is recognized suffering from major environmental deterioration, ecosystem disturbance, and congested living conditions with imposed pressures and constraints on the urban environment [14]. The Chinese cases are typical in urbanizing stages and supposed to trigger multiple complications between human demands and satisfaction. And urban greening was initiated in China to achieve harmony between people and nature [15]. However, the development of UGI for public use has been a recent phenomenon in Chinese cities [14]. For the former urgent situations in modern China, although with a late start and a relatively new take in modern scientific research, the number of related studies on UES identification and valuation is increasing rapidly [14], [16], and different types of UES had been fully covered, such as air purification, microclimate regulation, and recreation [6], [17-18]. However, among the discussions in terms of the type of service, methodologies, research perspectives, and other aspects [19], the elements of "urban dweller demands" are still barely mentioned, and related studies are scarce. With the intention of highquality life construction, whether these academic UES research directions could match urban dweller demand concerns in modern China should be urgently studied.

This study reviewed the Chinese academic concerns of UES provided by UGI and urban dweller demands. The two topics were reviewed separately through literature collection, and they were discussed afterwards by integrating them. First, specific types of services and demands were listed and given focus. Second, research perspectives of them were discussed to check research concerns and developments. Based on these and other topic concerns in research sites, scales and methodologies, our objective is to give comprehensive review to Chinese UES researches and their matches with demand concerns. By presenting the unique experiences shared by Chinese scholars, we believe that this study would help further sustainability and society

* Corresponding author: ${ }^{a}$ Liang Zhao 494885966@qq.com 
development by case examples providing and worldwide suggestions offering.

\section{Methodologies}

With the results of our self-pre-collection tests, "title word" was applied for its best function in the suitable articles, and Chinese and English articles were collected separately. The Chinese articles searched would be classified into the following two parts: (1) UES provided by UGI: journal articles with title words of "Urban/City 城市/市”, “Green/Forest/Park/Plant/Vegetation 绿地/森 林/公园/植物/植被”, and “Ecosystem Services 生态系 统服务”; and (2) urban dweller demands: journal publications with title words of “Urban/City 城市/市”, “Inhabitants/Citizen/Public 居民/市民/公众”, and “Demands/Needs/Requirements 需求/需要/要求”. Recognized as the most inclusive Chinese information and data resource, China Knowledge Resource Integrated Database (http://www.cnki.net) was selected for article searching [16]. Moreover, given that urbanization trade started from the beginning of the 1990s in China [14], articles with publishing year from 1990 to May 2015 were selected in the current study. Those studies with the aforementioned title words in English were also searched in the databases of Science Direct (http://www.sciencedirect.com/) and Springer (http://link.springer.com/) from 1990 to May 2015 because these databases were considered with great efforts. With similar concerns of former review studies that introducing Chinese scholar concerns and research works into world, only "published by Chinese authors in Chinese cities" results were selected [16]. As special administrative regions of China with different modern histories, Hong Kong and Macau were excluded from this research.

\section{Results}

\subsection{Literature review in UES concerns}

For various interpretations existing in UES concepts, this study reviewed the collected 105 articles (54 Chinese and 51 English articles). And as shown in Fig.1, a few articles qualified before the publishing of MA reports [8] but accumulated since 2008, with at least 10 publications every year.

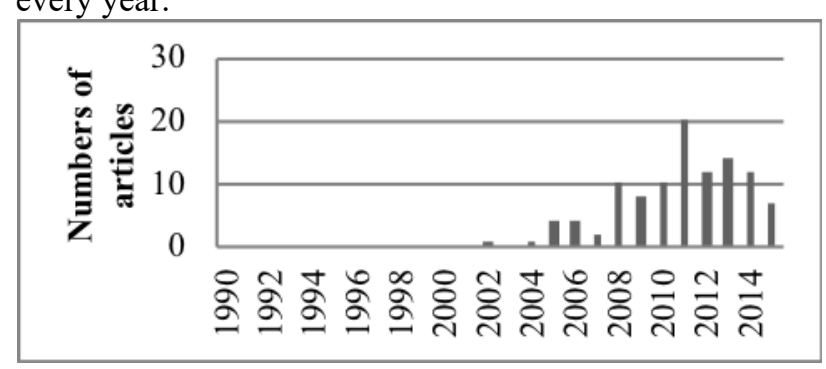

Fig. 1. Numbers of journal articles on "UES provided by UGI" between 1990 and May 2015.

\subsubsection{Literature review classified by UES types}

Considering the features in UGI and MA reports, this study focused on the detailed services that benefit urban dwellers. Consequently, several types of UES were all given attention and calculated. Among these ecosystem services, CSS seemed to be the most preferred because it was discussed in nearly half of all collections. Moreover, nearly $40 \%$ of the articles were concerned with soil and water conservation, and $33 \%$ of articles were concerned with air purification, which ranked third. Noise reduction was the least preferred because only six articles were found discussing it. The percentages of concern for other services of nature experience, pollution abatement in soil and water, microclimate regulation, biodiversity, recreation, and providing food were nearly equal, ranging from $10 \%$ to $25 \%$.

\subsubsection{Literature review classified by research perspectives}

This study specifically focused on "UGI management", "UGI planning", and "ecosystem sustainability" because they were assumed to be the most normal perspectives in UES research [14], [16]. Nearly $30 \%$ of the articles clearly mentioned contributing to UGI management, which was the highest among the three, and correspondingly, $23 \%$ in UGI planning and approximately $18 \%$ in ecosystem sustainability. In addition, we classified those articles with clear policy words (e.g., "eco-city", "green GDP", and "ecological civilization") under policy manager because they are strongly connected with recent Chinese policies. Results indicate that "policy manager" and the number of planners were found in roughly $15 \%$ percent of the articles. $50 \%$ of the articles had clear academic scholarly backgrounds, and in comparison, normal dwellers were only found in $6 \%$ of the articles, which was the least.

\subsubsection{Literature review classified by spatial sites}

With an overwhelming superiority, city-level studies comprised nearly $70 \%$ of the studies. Nearly $20 \%$ clearly discussed patch-level aspects. Region-level studies were also found in $10 \%$ of the articles included. Only $1 \%$ of the articles studied national-level aspects, and no globallevel UES studies from Chinese scholars could be found thus far. 


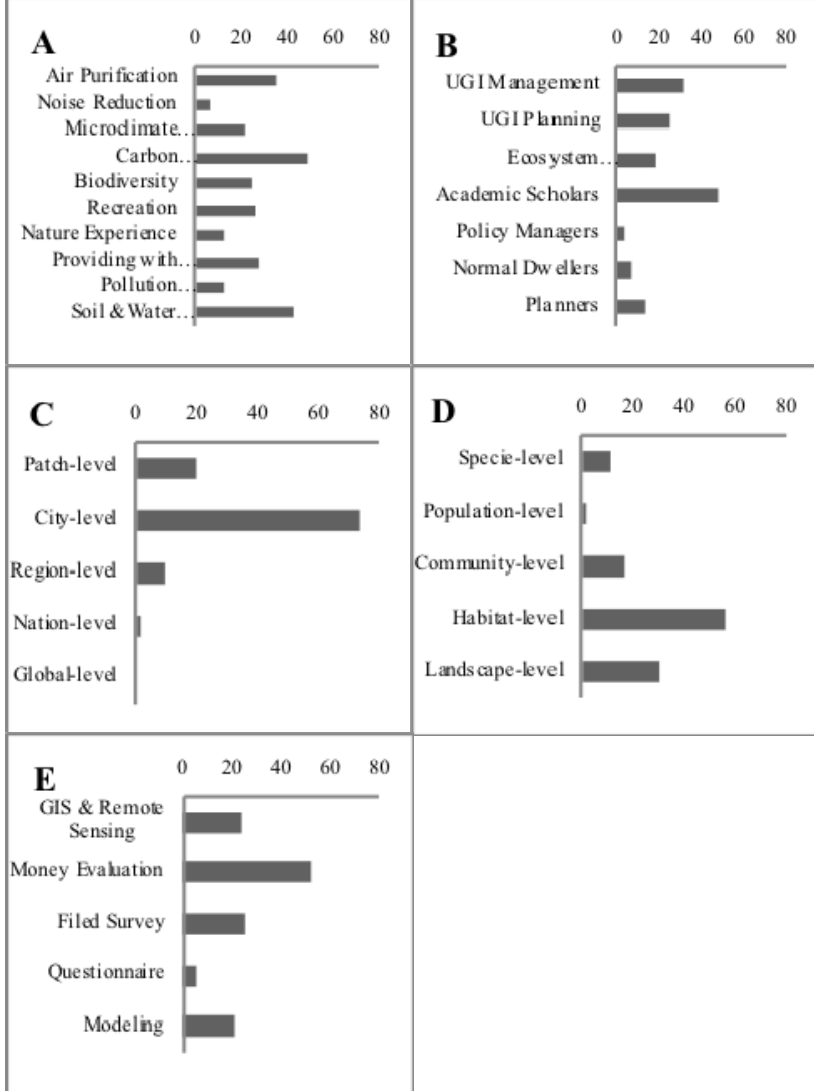

Fig. 2. Numbers of journal articles on "UES provided by UGI" with classification of "Ecosystem Services Sorts" (A), "Perspectives with Author Backgrounds" (B), "Spatial Sites"(C), "Ecological Scales" (D), and "Methodologies"(E). One article can be classified into more than one theme.

\subsubsection{Literature review classified by ecological scales}

Our collection shows that more than half of the UES studies were conducted at the habitat-level. The landscape-level was favored second, and communitylevel ranked third, with proportions of $30 \%$ and $16 \%$, respectively. Nearly $10 \%$ of the articles were discussed with specific species listed. Population-level studies were the least favored, within only $2 \%$ of the articles concerned.

\subsubsection{Literature review classified by research methodologies}

In considering the normal implementations, the methodologies of GIS and remote sensing, money evaluation, field survey, questionnaire, and modeling were give attention. Monetary value evaluation methods were the most preferred topics by Chinese scholars, and these methods were implemented in nearly half of the studies. Field survey, GIS and remote sensing, and modeling followed with no significant difference between one another, and they were found in $20 \%$ to $25 \%$ of the studies. Questionnaire was the least applied method, as only six results were found.

\subsection{Literature review in urban dweller demand concerns}

With a collection of 188 articles (162 Chinese articles and 26 English articles) and related analyses, we found that the number of articles generally increased with time, particularly since 2006 :

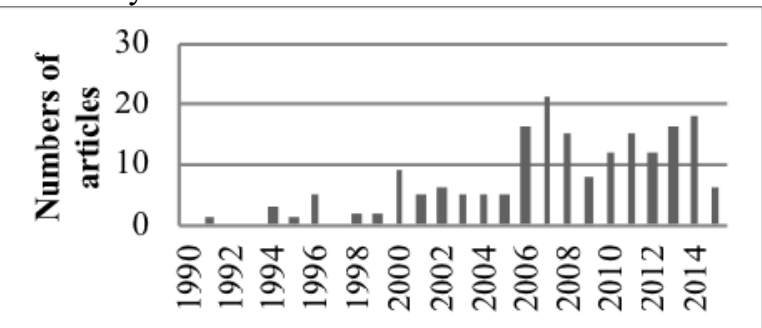

Fig. 3. Numbers of journal articles on "urban dweller demands" between 1990 and May 2015.

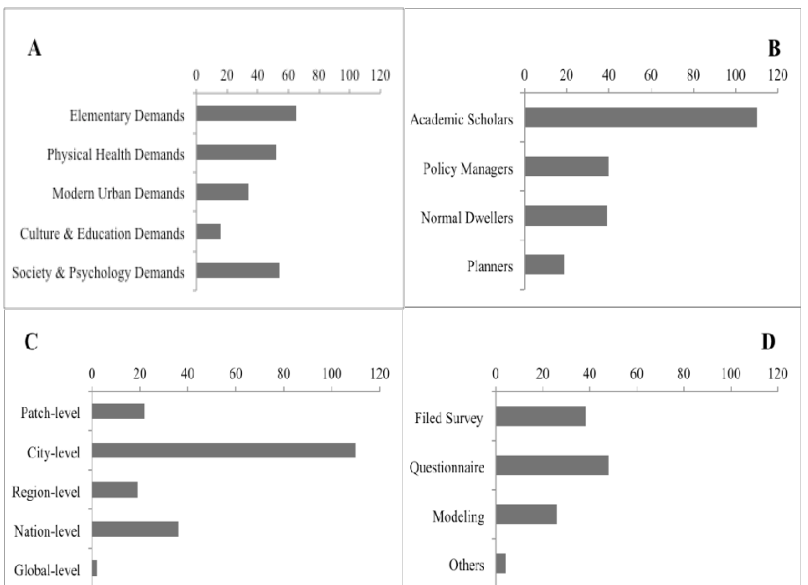

Fig. 4. Numbers of journal articles on "urban dweller demands" with classification of "Demands Sorts" (A), "Perspectives with Author Backgrounds" (B), "Spatial Sites"(C), and "Methodologies"(D). One article can be classified into more than one theme.

\subsubsection{Literature review classified by demand types}

Considering urban environmental features and the effects of urbanization on urban dwellers, we classified demands into five levels, namely, elementary demands, physical health demands, modern urban demands (special demands only occur in modern cities, such as urban transportations and urban infrastructures), cultural and educational demands, and societal and psychological demands. As a result of the classifications and counting, the basic elementary demands have always been given great attention in the last decades (35\% of all the studies), and water resources and living conditions were given the most attention. With increasing pressures in urban regions, societal and psychological demands were the second highest (30\% of all), and community tourism was mostly discussed because of its functions in releasing pressure. Physical health demands (28\%) were also given great attention, but an overwhelming majority only focused on medical care. Modern urban demands and cultural and educational demands were the last two needs, which were found in $18 \%$ and $9 \%$ of the articles, respectively. 


\subsubsection{Literature review classified by research perspectives}

With notable effects on articles of normal dwellers through viewpoints and discussions, academic scholars were the main speakers, which covered $60 \%$ of the journal articles. Moreover, roughly $20 \%$ of the articles highlighted the perspectives of policy discussions, policy suggestions, and government management reports. Studies from urban planners were the least number of studies, comprising less than $10 \%$ of the total number of articles.

\subsubsection{Literature review classified by spatial sites}

Approximately $60 \%$ of the articles selected city-level as their research site, and they have persisted in the last few decades. Nation-level (the entire China) (20\%) and patch-level (special regions, e.g. districts and specific buildings) $(12 \%)$ were the second and third most preferred topics. The global-level topics were barely found in studies of Chinese scholars (only 1\%).

\subsubsection{Literature review classified by methodologies}

Except normal text description, the most frequently applied methodologies were field survey, questionnaire, and modeling. New modern methods, such as GIS and remote sensing, were barely applied in demand studies because those researchers were unable to obtain direct data from urban dwellers.

\section{Discussion}

\subsection{Mismatches between UES type and dweller demand concern are spatially various in different regions and cities}

In our study, 58 cities and regions were mentioned in the UES articles and 69 respectively in those of demands. And detailed discussions of different regions and cities would be necessary because China has an unbalanced development with multiple complicated situations.

\subsubsection{Mismatches among different regions}

According to geographic and socioeconomic factors, China can mainly be classified into four regions, namely eastern region, middle region, northeastern region, and western region. Located in the most developed region and with the fastest urbanization through labor imports, the eastern region is with most intense humanenvironment interactions by $38 \%$ national population in only $8 \%$ land cover, as a result, $65 \%$ of the UES studies are focused here with $58 \%$ of national urban dweller concerns. The region has most articles focusing on air purification, microclimate regulation, pollution abatement in soil and water, soil and water conservation, and environmental services found here. And elementary, physical health, and modern urban demands were also highest in this region, correspondingly. The western region is disadvantaged in having the lowest population $(26 \%)$ but advantaged in having the largest land area $(68 \%)$. For fragile environment and geographic factors, the services of soil and water conservation and CSS were highly given attention. Moreover, elementary demands were significantly concerned, but higher leveled demands were relatively unvalued, such that no articles in cultural and educational demands were carried out. The middle region has the least number of UES articles $(7 \%)$ because it has the smallest land area $(11 \%)$. However, combined with the high demands in physical health, UES provided through air purification was also highly given attention. The northeastern region has the opposite situation in a relatively large land area (13\%) but with the least population (9\%). In addition, for biogeographic factors, significant high concerns on CSS were found here [data source [20]].

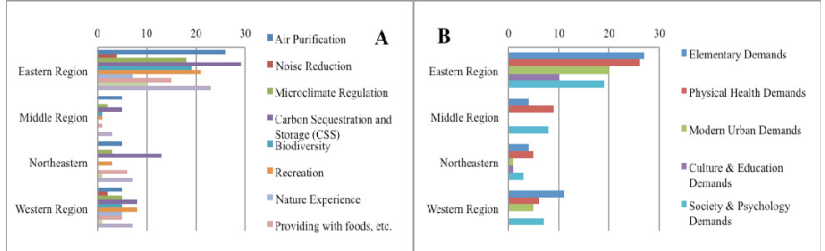

Fig. 5. Numbers of articles in each region by classifications of UES (A) and urban dweller demands (B)

\subsubsection{Mismatches among different cities}

Another spatially unbalanced situation in China lies in the developments among cities. We selected population as a classification factor for its direct effects on human demands. Moreover, by citing standards from the latest documents [21], we classified the referred cities into five levels, namely, first-level cities (with inter-city population of more than 10 million), second-level cities ( 5 to 10 million), third-level cities (1 to 5 million), fourth-level cities (500,000 to 1 million), and fifth-level cities (below 500,000). As shown in Fig.6, third-level cities were given the most concern, with the largest number of articles in UES (33\%) and urban dweller demands (37\%). The environment-related services and recreation services were relatively highest. Moreover, elementary, physical health, and societal and psychological demands were also highly given attention in those cities. However, in terms of the largest percentages in city numbers $(40 \%)$ and dweller population $(51 \%)$, both concerns in terms of services and demands still require improvement. First-level cities were the second in terms of attention, with $23 \%$ national articles in UES and 27\% national articles in demands. Environmental UES was highly given attention in those cities, but it definitely requires more focus on recreation and nature experience. Although those cities were the most highly developed in China, pressures of intense population (more than 10 million) on resource and energy and elementary demands (food, drinking water, living places, etc.) were still highly given attention (36\%). Second-level cities were the third most preferred topics in both services and demand studies. For those cities that normally have the most rapid development in 
modern China and are considered to have the highest migration imports, the concerns of modern construction (particularly infrastructure) were relatively highest. Moreover, environmental UES was strongly concerned with the associated environmental deterioration. Although fourth-level cities have the second largest population percentage, national strategic factors engendered relatively less concerns in both service and demands studies. Assuming the same geographical factors, fifth-level cities were somehow mismatched, with only $3 \%$ of the interests in urban dweller demands but as high as 14\% UES articles found [population data source [20]].

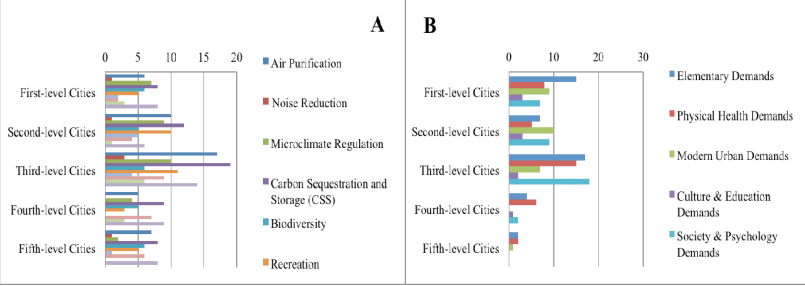

Fig. 6. Numbers of articles in cities by classifications of UES (A) and urban dweller demands (B)

\subsubsection{Spatial distribution and imbalance between UES and demands}

Overall, with the UES studies mostly found in the eastern region and in cities with large populations, they are found significantly different between regions and obviously different among cities. Although no obvious spatial differences were found in demands concerns, but the largest national mismatches would be found in the high societal and psychological demands but in low UES benefits in recreation and nature experiences.

\subsection{Environment were focused on holistic and systemic thinking in research perspectives}

Accompanying socioeconomic accumulation, severe environment deterioration and biodiversity loss are prevalent in China. And for their enormous potential in reducing environmental pressure [12], more than $60 \%$ of the UES articles were found to be concerned with direct environmental services. Among the topics of the articles, water and soil conservation, air purification, and microclimate regulation were the top three topics, with discussion and analysis found in $40 \%, 33 \%$, and $20 \%$ of the collected articles, respectively. Biodiversity services were also the concern of $24 \%$ of the articles, which mostly discussed native species loss and biodiversity conservation [21-23]. Combining other numbers of articles concerned with pollution abatement in soil and water and noise reduction, we can conclude that the environmental problems of both services and demands are being highly given attention in modern China [24]. Besides of these, those articles were classified into "policy managers", "academic scholars", "planners", and "normal dwellers" by perspective concerns. Although academic scholars were considered as main speakers, the viewpoints of policy managers also played significant roles because China is strongly influenced by government policies. The opinions of Chinese planners were not highly valued because they normally focused more on aesthetics impression but not on scientific dynamics, such as nature and ecological processes [25]. However, this situation is unreasonable because normal dwellers were relatively underestimated, particularly in demand studies. Other scholars also discussed this unequal phenomenon between policy managers and normal dwellers and attributed the situation to the powerful Chinese political control and holistic and systemic thinking. Holistic and systemic thinking has been identified as a feature of Chinese urban ecology studies [16], and it can also be proven by our collection, with roughly $60 \%$ and $20 \%$ of demand studies at the city-level and nation-level, respectively, and more than $50 \%$ and approximately $30 \%$ of the UES at the habitatlevel and landscape-level, respectively. Political control and holistic and systemic thinking were reflected in the mismatches between demands and services. However, nearly $50 \%$ of the UES articles focused on CSS because of the lack of demands on carbon. Apparently, carbon would not be highly demanded by normal dwellers but is widely given attention by policy managers, academic scholars, and planners only because of the policy effects.

\subsection{Monetary value evaluation, GIS and remote sensing as dominate methodologies in UES studies}

This section chiefly focuses on the methodologies implemented in UES studies. Although no standardized methodology has been acknowledged in UES evaluation [14], an overwhelming number of studies preferred monetary value evaluation and GIS and remote sensing, which were implemented in roughly $50 \%$ and $23 \%$ of the articles, respectively. In discussing the reasons for the use of these methodologies, financial effects and data resources need to be given attention. Chinese UGI is maintained through financial support from the government because private perks are lacking in a socialist system. In China, inadequate financial support has chronically constrained UGI development [14], and scholars have not identified other better patterns to caution the value of UES expecting direct monetary statements. In addition to the financial reason of labor costs, limitations in data gathering were found in most of the collected articles mentioned. Moreover, compared with traditional field survey, GIS and remote sensing have advantages in implementation with various models and forms of programming development. Although they have commonalities in extensive implementations, obvious differences exist in monetary value evaluations and GIS and remote sensing, with monetary value evaluations applied in nearly $65 \%$ of the Chinese articles. In terms of technological reasons, $75 \%$ of GIS and remote sensing methodologies were performed in the eastern regions and $85 \%$ in cities with more than one million inhabitants. 


\section{Conclusions}

In this article, studies on UES were reviewed with backgrounds of dweller demands under consideration. Although the number of related articles basically increased with time but spatial imbalance were observed among regions and cities. Moreover, relative low concerns on recreation and nature experiences were found nationally when compared with high societal and psychological demands. Another typical feature in China is the significantly high concerns on environment deterioration with holistic and systemic thinking, and monetary value evaluation was comparatively widely preferred besides GIS and remote sensing because of crucial roles of applying financial support. Moreover, the balance between recreation \& nature experience UES and socioeconomic demands should be more concerned, and more normal dwellers should be heard with state-ofthe-art methodologies being encouraged.

\section{References}

1. G. C. Nelson, E. Bennett, A. a. Berhe, K. Cassman, R. DeFries, T. Dietz, A. Dobermann, A. Dobson, A. Janetos, M. Levy, D. Marco, N. Nakicenovic, B. O’Neill, R. Norgaard, G. Petschel-Held, D. Ojima, P. Pingali, R. Watson, and M. Zurek, "Anthropogenic drivers of ecosystem change: An overview," Ecology and Society, vol. 11, no. 2, pp. 526-556, 2006.

2. Landscape Institute, Green infrastructure: connected and multifunctional landscapes. London: The Landscape Institute, 2009.

3. H. Setälä, V. Viippola, A. L. Rantalainen, A. Pennanen, and V. Yli-Pelkonen, "Does urban vegetation mitigate air pollution in northern conditions?," Environmental Pollution, vol. 183, pp. 104-112, 2012.

4. G. S. Cumming, "Spatial resilience: integrating landscape ecology, resilience, and sustainability," Landscape Ecology, vol. 26, no. 7, pp. 899-909, 2011.

5. A. Kaczorowska, "Ecosystem Services and Urban Resilience-Case of Stockholm.," in 2014 ISOCARP International Planning Congress, 23-26 September 2014, Gdynia, Poland, 2014, pp. 1-9.

6. C. Y. Jim and W. Y. Chen, "Recreation-amenity use and contingent valuation of urban greenspaces in Guangzhou, China," Landscape and Urban Planning, vol. 75, no. 1-2, pp. 81-96, 2006.

7. C. Y. Jim and X. Shan, "Socioeconomic effect on perception of urban green spaces in Guangzhou, China," Cities, vol. 31, pp. 123-131, 2013.

8. Millennium EA, Ecosystems and human well-being, vol. 5. Island Press Washington, DC, 2005.

9. M. Potschin and R. Haines-Young, "Landscapes, sustainability and the place-based analysis of ecosystem services," Landscape Ecology, vol. 28, no. 6, pp. 10531065, 2013.

10. J. Wu, "Landscape sustainability science: Ecosystem services and human well-being in changing landscapes," Landscape Ecology, vol. 28, pp. 999-1023, 2013.

11. F. Baró, D. Haase, E. Gómez-Baggethun, and N. Frantzeskaki, "Mismatches between ecosystem services supply and demand in urban areas: A quantitative assessment in five European cities," Ecological Indicators, vol. 55, pp. 146-158, 2015.

12. D. Rodríguez-Rodríguez, J. H. Kain, D. Haase, F. Baró, and A. Kaczorowska, "Urban self-sufficiency through optimised ecosystem service demand. A utopian perspective from European cities," Futures, vol. 70, pp. 13-23, 2015.

13. S. Wolff, C. J. E. Schulp, and P. H. Verburg, "Mapping ecosystem services demand: A review of current research and future perspectives," Ecological Indicators, vol. 55, pp. 159-171, 2015.

14. C. Y. Jim and W. Y. Chen, "Ecosystem services and valuation of urban forests in China," Cities, vol. 26, no. 4, pp. 187-194, 2009.

15. B. Fan and Z. Li, "Construction of Urban Forest and Inhabited Entironment in History of China (in Chinese)," Journal of Chinese Urban Dorestry, vol. 3, no. 1, pp. 5761, 2005.

16. J. Wu, Wei-Ning Xiang, and J. Zhao, "Urban ecology in China: Historical developments and future directions," Landscape and Urban Planning, vol. 125, pp. 222-233, 2014.

17. J. Yang, J. McBride, J. Zhou, and Z. Sun, "The urban forest in Beijing and its role in air pollution reduction," Urban Forestry \& Urban Greening, vol. 3, no. 2, pp. 6578, 2004.

18. X. Li, W. Zhou, Z. Ouyang, W. Xu, and H. Zheng, "Spatial pattern of greenspace affects land surface temperature: Evidence from the heavily urbanized Beijing metropolitan area, China," Landscape Ecology, vol. 27, no. 6, pp. 887-898, 2012.

19. J. $\mathrm{Xu}, \mathrm{Z}$. Liu, L. Song, and Y. Hu, "Evaluation on ecological services of urban green space in Guangzhou City of South China based on remote sensing (in Chinese)," Chinese Journal of Ecology, vol. 31, no. 2, pp. 440-445, 2012.

20. State Council of the P.R.China, On the adjustment criteria for the classification of city size (in Chinese). P.R.China: Paper Reports of State Council of P.R.China.

21. F. Kong, H. Yin, N. Nakagoshi, and Y. Zong, "Urban green space network development for biodiversity conservation: Identification based on graph theory and gravity modeling," Landscape and Urban Planning, vol. 95, no. 1-2, pp. 16-27, 2010.

22. Y. Hou, S. Zhou, B. Burkhard, and F. Müller, "Science of the Total Environment Socioeconomic in $\mathrm{fl}$ uences on biodiversity, ecosystem services and human well-being: A quantitative application of the DPSIR model in Jiangsu , China," Science of the Total Environment, vol. 490, pp. 1012-1028, 2014.

23. W. Li, Z. Ouyang, X. Meng, and X. Wang, "Plant species composition in relation to green cover configuration and function of urban parks in Beijing, China," Ecological Research, vol. 21, no. 2, pp. 221-237, 2006.

24. C. Y. Jim and W. Y. Chen, "Perception and attitude of residents toward urban green spaces in Guangzhou (China)," Environmental Management, vol. 38, no. 3, pp. 338-349, 2006.

25. B. Chen and S. Lu, "Valuing ecological services of green space of West Lake scenic area in Hangzhou (in Chinese).," Journal of Zhejiang University (Agriculture and Life Sciences), vol. 35, no. 6, pp. 686-690, 2009. 